\title{
Combination neratinib (HKI-272) and paclitaxel therapy in patients with HER2-positive metastatic breast cancer
}

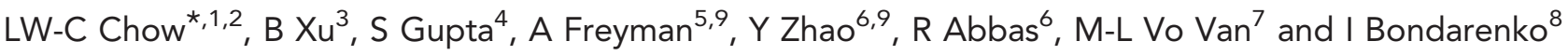 \\ ${ }^{1}$ UNIMED Medical Institute, Comprehensive Centre for Breast Diseases, Hong Kong, China; ${ }^{2}$ Organisation for Oncology and \\ Translational Research (OOTR), Hong Kong, China; ${ }^{3}$ Cancer Hospital, Chinese Academy of Medical Sciences, Beijing, China; \\ ${ }^{4}$ Department of Medical Oncology, Tata Memorial Hospital, Mumbai, India; ${ }^{5}$ Clinical Research and Development, Pfizer Inc, \\ Cambridge, MA, USA; ${ }^{6}$ Clinical Pharmacology, Prizer Inc, Collegeville, PA, USA; ${ }^{7}$ Pfizer Global Research and Development, Paris, \\ France and ${ }^{8}$ City Multifield Clinical Hospital, Dnipropetrovsk State Medical Academy, Dnipropetrovsk, Ukraine
}

Introduction: Neratinib is a potent irreversible pan-ErbB tyrosine kinase inhibitor that has demonstrated antitumour activity and an acceptable safety profile in patients with human epidermal growth factor receptor (HER)-2-positive breast cancer and other solid tumours.

Methods: This was a phase I/II, open-label, two-part study. Part 1 was a dose-escalation study to determine the maximum tolerated dose (MTD) of neratinib plus paclitaxel in patients with solid tumours. Part 2 evaluated the safety, efficacy, and pharmacokinetics of the combination at the MTD in patients with HER2-positive breast cancer.

Results: Eight patients were included in the dose-escalation study; no dose-limiting toxicities were observed, and an MTD of oral neratinib $240 \mathrm{mg}$ once daily plus intravenous paclitaxel $80 \mathrm{mg} \mathrm{m}^{-2}$ on days 1,8 , and 15 of each 28-day cycle was determined. A total of 102 patients with HER2-positive breast cancer were enrolled in part 2. The overall median treatment duration was 47.9 weeks (range: 0.1-147.3 weeks). Common treatment-emergent adverse events (all grades/grade $\geqslant 3$ ) included diarrhoea (92\%/29\%; none grade 4), peripheral sensory neuropathy (51\%/3\%), neutropenia (50\%/20\%), alopecia (46\%/0\%), leukopenia (41\%/18\%), anaemia (37\%/8\%), and nausea (34\%/1\%). Three (3\%) patients discontinued treatment due to an adverse event (mouth ulceration, left ventricular ejection fraction reduction, and acute renal failure). Among the 99 evaluable patients in part 2 of the study, the overall response rate (ORR) was 73\% (95\% confidence interval (Cl): 62.9-81.2\%), including 7 (7\%) patients who achieved a complete response; an additional 9 (9\%) patients achieved stable disease for at least 24 weeks. ORR was $71 \%$ among patients with 0/1 prior chemotherapy regimen for metastatic disease and no prior lapatinib, and $77 \%$ among those with 2/3 prior chemotherapy regimens for metastatic disease with prior lapatinib permitted. Kaplan-Meier median progression-free survival was 57.0 weeks (95\% Cl: 47.7-81.6 weeks). Pharmacokinetic analyses indicated no interaction between neratinib and paclitaxel.

Conclusion: The combination of neratinib and paclitaxel was associated with higher toxicity than that of neratinib as a single agent, but was manageable with antidiarrhoeal agents and dose reductions in general. The combination therapy also demonstrated a high rate of response in patients with HER2-positive breast cancer. A phase III trial is ongoing to assess the benefit and risk of this combination in the first-line setting.

\footnotetext{
*Correspondence: Dr LW-C Chow; E-mail: Iwcchow@ootr.org

${ }^{9}$ Amy Freyman and Yonggang Zhao were employees of Pfizer during the conduct of the study and initiation of the manuscript, but are no longer employed by Pfizer.
}

Received 13 November 2012; revised 12 March 2013; accepted 1 April 2013; published online 30 April 2013

(c) 2013 Cancer Research UK. All rights reserved 0007-0920/13 
The long-term survival of patients with metastatic breast cancer is traditionally low (Jemal et al, 2010). Human epidermal growth factor receptor (HER)-2 represents an important target for the treatment of breast cancer, as increased HER2 expression is observed in approximately $20-30 \%$ of breast cancers and has been shown to correlate with more aggressive tumours (Slamon et al, 1987). The introduction of HER2-targeted therapies, such as trastuzumab and lapatinib, has improved outcomes for patients with advanced HER2-positive breast cancer (Slamon et al, 2001; Burstein et al, 2008; Cameron et al, 2008; Di Leo et al, 2008; Toi et al, 2009). However, not all patients respond to anti-HER2 agents, whereas others develop drug resistance, shown by limited times to progression and overall survival in clinical studies (Eiermann, 2001; Slamon et al, 2001; Marty et al, 2005; Geyer et al, 2006; Robert et al, 2006; Burstein et al, 2007; Cameron et al, 2008; Di Leo et al, 2008; Blackwell et al, 2010; Andersson et al, 2011). Therefore, the development of new potent and selective anti-HER2 agents is needed, particularly for patients whose prior treatment has failed. Further, antitumour activity may be achieved with a regimen that includes anti-HER2 therapy in combination with chemotherapy or other targeted agents, if the combination is tolerable at therapeutic dose levels.

Neratinib (HKI-272) is a potent, orally administered irreversible tyrosine kinase inhibitor of the ErbB family of receptors (epidermal growth factor receptor (EGFR)/HER1, HER2, and HER4) that covalently binds to the cytoplasmic domain of ErbB receptors, thereby preventing downstream signalling (Rabindran et al, 2004; Tsou et al, 2005). Neratinib has the ability to irreversibly inhibit multiple ErbB receptors and effectively inhibits the proliferation of EGFR- and HER2-expressing cells that are resistant to treatment with first-generation ErbB receptor tyrosine kinase inhibitors (e.g., gefitinib; Kwak et al, 2005). Neratinib has demonstrated antitumour activity in phase I and II clinical studies in patients with HER2-positive breast cancer, including ones with or without prior exposure to trastuzumab, as well as in patients with other solid tumours (Wong et al, 2009; Burstein et al, 2010).

Potential antitumour activity of neratinib in combination with paclitaxel is suggested from in vitro and in vivo data demonstrating that gefitinib (EGFR inhibitor) combined with paclitaxel (taxane) yields inhibition and apoptosis of EGFR-expressing non-small-cell lung cancer cell line and xenograft tumour models (Sirotnak et al, 2000; Van Schaeybroeck et al, 2006). This phase I/II, open-label, two-part study determined the maximum tolerated dose (MTD) of neratinib in combination with paclitaxel and assessed the safety, efficacy, and pharmacokinetics of this combination in patients with HER2-positive metastatic breast cancer.

\section{MATERIALS AND METHODS}

Patient population. Adults aged 18 years and older were eligible for enrolment. In part 1 of the study, patients were required to have confirmed diagnosis of a solid tumour. In part 2, patients were required to have confirmed diagnosis of stage IV HER2-positive breast cancer (confirmed with fluorescent in situ hybridisation or immunohistochemistry score of $\geqslant 3$ ) and prior trastuzumab therapy in the neoadjuvant, adjuvant, or metastatic setting (unless trastuzumab was contraindicated or unavailable); no more than three prior cytotoxic chemotherapy regimens in the metastatic setting were permitted. Patients in both study parts were required to have at least one measurable lesion by modified Response Evaluation Criteria In Solid Tumors (RECIST) guidelines, version 1.0; an Eastern Cooperative Oncology Group Performance Status score of 0 or 1 ; left ventricular ejection fraction within normal limits; adequate haematologic, hepatic, and renal laboratory values; and, for women of child-bearing potential, a negative pregnancy test result and willingness to use contraceptives. Full inclusion and exclusion criteria are summarised in Supplementary Table A1.

This study was conducted in accordance with the Declaration of Helsinki. All patients provided written informed consent before study participation, and the protocol was approved by the institutional review board at each study site.

Study design. This was a phase I/II, open-label, two-part study. Part 1 was a dose-escalation study of a standard $3+3$ design in which successive cohorts of three to six patients with advanced solid tumours were evaluated for safety and determination of the MTD of combination treatment. Patients were administered ascending daily oral doses of neratinib (either 160 or $240 \mathrm{mg}$ ) in combination with intravenous paclitaxel $\left(80 \mathrm{mg} \mathrm{m}^{-2}\right)$ on days 1,8 , and 15 of each 28-day cycle. Each cohort of three to six patients was assessed for safety and dose-limiting toxicities (DLTs) over 28 days before the escalation to the next dose level. If one of three patients experienced a DLT, the cohort was expanded to six patients. The MTD was defined as the highest dose at which no more than one patient experienced a DLT; therefore, if two or more patients experienced a DLT, dose escalation was stopped and the prior dose level was considered the MTD. A DLT included any of the following treatment-related events occurring during the first 28 days of therapy: grade $3 / 4$ non-haematologic toxicity (except grade 3 asthenia unless lasting $>3$ days, grade 3 nausea or vomiting unless on optimal medical therapy, and grade 3 diarrhoea unless lasting $>2$ days on optimal medical therapy (Benson et al, 2004) or associated with fever or dehydration); grade 4 neutropenia lasting at least 7 days or associated with fever; grade $3 / 4$ infection in the context of grade $3 / 4$ neutropenia; and delayed recovery to grade $0 / 1$ toxicity that requires treatment interruption of more than 3 weeks.

Part 2 of this study evaluated the efficacy, safety, and pharmacokinetics of neratinib plus paclitaxel in patients with HER2-positive breast cancer at the MTD and schedule established in part 1. The patients were divided into two groups based upon prior anticancer therapy: group A included patients who had received no more than one prior cytotoxic chemotherapy regimen for metastatic disease and no prior lapatinib exposure, whereas group B included patients who had received no more than three prior cytotoxic chemotherapy regimens for metastatic disease with prior lapatinib exposure permitted. The primary objective for part 2 was to estimate the probability of overall response (complete + partial responses). The secondary objectives of part 2 were to confirm the MTD identified in part 1 of the study, to obtain safety and pharmacokinetic information, and to assess additional efficacy parameters, including the probability of clinical benefit (complete/ partial response + stable disease $\geqslant 24$ weeks), the probability of progression-free survival (PFS) at week 16, and duration of response.

Study assessments. Safety was assessed by physical exams, laboratory assessments, and adverse event reporting. Adverse events were reported at each study visit and graded for severity according to the National Cancer Institute Common Terminology Criteria for Adverse Events, version 3.0. Serious adverse events were reported until 28 days after the last dose of study treatment and were followed until resolution.

Tumour assessments were performed at baseline and then every two cycles ( 8 weeks) throughout the study, or as clinically indicated (based on protocol amendment). Measurable (target) and nonmeasurable (non-target) lesions were documented by computed tomography or magnetic resonance imaging scans and followed using the same assessment method throughout the study. Response was assessed by the investigators based on modified RECIST guidelines, with complete and partial responses requiring confirmation by a repeat assessment at least 4 weeks after initial 
documentation of the response. Stable disease could first be assessed no sooner than 8 weeks after the first dose of study drug.

For pharmacokinetic assessments, blood samples were collected predose and at $1,2,4,6,8$, and $21-24$ h post-dose on day 15 of cycle 1 for analyses of neratinib plasma concentrations. Pharmacokinetic analyses were performed using a noncompartmental method.

Statistical analyses. In part 1 , the sample size was determined by clinical rather than statistical considerations. Considering the true DLT rates were $0.1,0.2,0.3,0.4$, and 0.5 for the cohort sizes of three to six patients, there would be probabilities of $91 \%, 71 \%$, $49 \%, 31 \%$, and $17 \%$, respectively, for escalation to the next full dose. In part 2, the uninteresting overall response rate (ORR) was set at $35 \%$ and the sufficiently promising ORR was set at $50 \%$, based on previously reported data from phase III studies of trastuzumab plus paclitaxel and lapatinib plus paclitaxel in HER2positive breast cancer (Di Leo et al, 2008; Seidman et al, 2008). The overall probability of accepting neratinib plus paclitaxel for further study under the null hypothesis was approximately 0.10 . To compensate for the expected dropout or nonevaluable rate of $15 \%$, approximately 60 patients were to be enrolled in group A, providing approximately $79 \%$ power to detect an ORR of $50 \%$. An additional 25 patients were to be enrolled in group B to evaluate the safety and efficacy of neratinib in pretreated patients.
All patients who received at least one dose of neratinib were included in the safety analysis. Patients who completed at least one post-baseline tumour assessment and received at least 2 weeks of neratinib treatment and two doses of paclitaxel were evaluable for efficacy; efficacy was also evaluated in the intent-to-treat (ITT) population, which included all enrolled patients. Categorical variables (i.e., response) were presented as counts and percentages along with associated 95\% confidence intervals (CIs), whereas continuous variables were presented using descriptive statistics. Time-to-event end points (i.e., PFS, duration of response) were analysed using the Kaplan-Meier method; median PFS and the corresponding 95\% CI were calculated. PFS was calculated from the date of first dose of study drug administered until the date of first documentation of recurrence/progression or death due to any cause; patients were otherwise censored at the last evaluation. The duration of response was calculated from the date of first documented response until the first date of disease progression.

\section{RESULTS AND DISCUSSION}

Patients. A total of 110 patients with solid tumours $(n=8)$ or HER2-positive breast cancer $(n=102$; including 71 in group A and 31 in group B) were enrolled in the study. The baseline

\begin{tabular}{|c|c|c|c|c|c|}
\hline \multirow[b]{2}{*}{ Characteristic } & \multicolumn{2}{|c|}{ Part 1} & \multicolumn{2}{|c|}{ Part 2} & \multirow[b]{2}{*}{$\begin{array}{c}\text { Total } \\
(\mathbf{N}=110)\end{array}$} \\
\hline & $\begin{array}{c}\text { Neratinib } \\
160 \mathrm{mg}+\text { paclitaxel } \\
(n=3)\end{array}$ & $\begin{array}{c}\text { Neratinib } \\
240 \text { mg }+ \text { paclitaxel } \\
(n=5)\end{array}$ & $\begin{array}{l}\text { Group } A^{a} \\
(n=71)\end{array}$ & $\begin{array}{c}\text { Group } B^{b} \\
(n=31)\end{array}$ & \\
\hline $\begin{array}{l}\text { Median age (range), years } \\
\quad<65 \text { Years, } n(\%) \\
\geqslant 65 \text { Years, } n(\%) \\
\text { Female sex, } n(\%)\end{array}$ & $\begin{aligned} 61 & (40-68) \\
2 & (67) \\
1 & (33) \\
1 & (33)\end{aligned}$ & $\begin{array}{c}44(37-64) \\
5(100) \\
0 \\
2(40)\end{array}$ & $\begin{array}{l}49(20-76) \\
67(94) \\
4(6) \\
71(100)\end{array}$ & $\begin{array}{c}51(36-63) \\
31(100) \\
0 \\
31(100)\end{array}$ & $\begin{array}{c}50.5(20-76) \\
105(95) \\
5(5) \\
105(95)\end{array}$ \\
\hline \multicolumn{6}{|l|}{ Ethnicity, n (\%) } \\
\hline $\begin{array}{l}\text { Asian } \\
\text { White } \\
\text { Other }\end{array}$ & $\begin{array}{c}2(67) \\
0 \\
1(33)\end{array}$ & $\begin{array}{c}2(40) \\
3(60) \\
0\end{array}$ & $\begin{array}{c}48(68) \\
22(31) \\
1(1)\end{array}$ & $\begin{aligned} 25 & (81) \\
5 & (16) \\
1 & (3)\end{aligned}$ & $\begin{array}{c}77(70) \\
30(27) \\
3(3)\end{array}$ \\
\hline $\begin{array}{l}\text { Stage III/IV disease at diagnosis, n (\%) } \\
\text { ER/PR-positive disease, } n(\%)\end{array}$ & $\begin{array}{l}2(67) \\
1(33)\end{array}$ & $\begin{array}{c}3(60) \\
0\end{array}$ & $\begin{array}{l}36(51) \\
36(51)\end{array}$ & $\begin{array}{l}12(39) \\
20(65)\end{array}$ & $\begin{array}{l}53(48) \\
57(52)\end{array}$ \\
\hline \multicolumn{6}{|l|}{ ECOG performance status, $n(\%)$} \\
\hline $\begin{array}{l}0 \\
1\end{array}$ & $\begin{array}{l}2(67) \\
1(33)\end{array}$ & $\begin{array}{l}3(60) \\
2(40)\end{array}$ & $\begin{array}{l}31(44) \\
40(56)\end{array}$ & $\begin{array}{r}22(71) \\
9(29)\end{array}$ & $\begin{array}{l}58(53) \\
52(47)\end{array}$ \\
\hline \multicolumn{6}{|c|}{ No. of prior chemotherapy regimens, ${ }^{c}$ n (\%) } \\
\hline $\begin{array}{l}0 \\
1 \\
2 \\
3 \\
>3\end{array}$ & $\begin{array}{c}0 \\
2(67) \\
1(33) \\
0 \\
0\end{array}$ & $\begin{array}{c}0 \\
2(40) \\
0 \\
1(20) \\
2(40)\end{array}$ & $\begin{array}{c}15(21) \\
30(42) \\
20(28) \\
4(6) \\
2(3)\end{array}$ & $\begin{array}{r}0 \\
0 \\
9(29) \\
15(48) \\
7(23)\end{array}$ & $\begin{array}{l}15(14) \\
34(31) \\
30(27) \\
20(18) \\
11(10)\end{array}$ \\
\hline $\begin{array}{l}\text { Prior radiotherapy, } n(\%) \\
\text { Prior trastuzumab therapy, }{ }^{c} n(\%) \\
\text { Prior lapatinib therapy, }{ }^{c} n(\%) \\
\text { Prior endocrine therapy, }{ }^{c} n(\%) \\
\text { Prior taxane therapy, }{ }^{c} n(\%)\end{array}$ & $\begin{array}{c}2(67) \\
0 \\
0 \\
0 \\
1(33)\end{array}$ & $\begin{array}{l}3(60) \\
1(20) \\
1(20) \\
0 \\
2(40)\end{array}$ & $\begin{array}{c}40(56) \\
18(25) \\
0 \\
24(34) \\
34(48)\end{array}$ & $\begin{array}{l}20(65) \\
12(39) \\
14(45) \\
16(52) \\
30(97)\end{array}$ & $\begin{array}{l}65(59) \\
31(28) \\
15(14) \\
40(36) \\
67(61)\end{array}$ \\
\hline 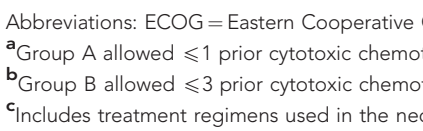 & $\begin{array}{l}\text { cology Group; } E R=\text { estrogen } \\
\text { rapy regimen for metastatic } d \\
\text { rapy regimens for metastatic } \\
\text { juvant, adjuvant, or metastati }\end{array}$ & $\begin{array}{l}\text { eeptor; } \mathrm{PR}=\text { progesterone rec } \\
\text { ase. } \\
\text { ease, with prior lapatinib perr } \\
\text { etting. }\end{array}$ & & & \\
\hline
\end{tabular}


demographic and disease characteristics for patients in both parts of the study are shown in Table 1 . This patient population includes those who received study treatment in both the first-line setting and in the second-line and greater settings.

Dose escalation (part 1). Eight patients with solid tumours were enrolled in part 1 of the study, including three patients enrolled in the initial cohort for neratinib $160 \mathrm{mg}$ plus paclitaxel and five patients enrolled in the subsequent cohort for neratinib $240 \mathrm{mg}$ plus paclitaxel. There were no DLTs observed in either cohort, and both dose regimens were well tolerated; therefore, the MTD was determined to be oral neratinib $240 \mathrm{mg}$ once daily plus intravenous paclitaxel $80 \mathrm{mg} \mathrm{m}^{-2}$ on days 1,8 , and 15 of each 28 -day cycle, corresponding to the full recommended dose previously determined for neratinib as monotherapy (Burstein et al, 2010) and a paclitaxel dose commonly used in other combination regimens (Perez et al, 2005; Furukawa et al, 2006; Gasparini et al, 2007; Han et al, 2009; Horiguchi et al, 2009; Andre et al, 2010). This combination was further evaluated at the MTD in part 2.

Treatment summary (parts 1 and 2). Treatment summaries for parts 1 and 2 are shown in Table 2. Overall, 90 patients discontinued treatment; reasons for stopping treatment included disease progression $(n=75(68 \%))$, patient request $(n=7(6 \%))$, death $(n=3(3 \%))$, adverse event $(n=2(2 \%))$, investigator request $(n=2(2 \%))$, and other $(n=1(1 \%))$. The median treatment duration of neratinib (parts 1 and 2) was 47.9 weeks (range: 0.1-147.3 weeks), with a median dose intensity of neratinib $239.6 \mathrm{mg}$ per day (range: $100.5-241.1 \mathrm{mg}$ per day). The median treatment duration of paclitaxel was 29.6 weeks (range: 1.0-97.1 weeks), with a median dose intensity of paclitaxel $213.5 \mathrm{mg} \mathrm{m}^{-2}$ per cycle (range: $78.7-245.1 \mathrm{mg} \mathrm{m}^{-2}$ per cycle). Dose reductions of neratinib and paclitaxel, respectively, were required by 21 (19\%) and $41(37 \%)$ patients and temporary dose delays were required by $58(53 \%)$ and $71(65 \%)$ patients.
Safety and tolerability (parts 1 and 2). The most common nonhaematologic treatment-emergent adverse events during the study (including three patients from part 1 who received neratinib $160 \mathrm{mg}$ per day plus paclitaxel) were diarrhoea (92\%), peripheral sensory neuropathy (51\%), alopecia (46\%), and nausea (34\%); common haematologic adverse events included neutropenia (50\%), leukopenia (41\%), and anaemia (37\%; Table 3 ). The most common grade $3 / 4$ treatment-emergent adverse events ( $\geqslant 5 \%$ of patients) were diarrhoea (29\%), neutropenia (20\%), leukopenia (18\%), and anaemia (8\%). The median time to onset of diarrhoea was 3 days (range: 1-583 days). Events of diarrhoea were typically transient in nature, with a median cumulative duration of diarrhoea of 35.5 days (range: 1-737 days) and a majority $(73 \%)$ of patients who reported diarrhoea experiencing resolution of their diarrhoea as of the time of this analysis. There were no grade 4 events of diarrhoea reported and none of the patients discontinued treatment due to diarrhoea. On treatment, $6(5 \%)$ patients experienced a prolonged QTc interval greater than $500 \mathrm{~ms}$ and $19(17 \%)$ patients experienced a QTc interval increased greater than $60 \mathrm{~ms}$ from baseline.

Throughout the study, $45 \%$ of patients required a dose reduction of neratinib and/or paclitaxel due to an adverse event and $72 \%$ of patients required a temporary interruption of study medication due to an adverse event. Adverse events leading to dose reduction/temporary interruption in at least $5 \%$ of patients included neutropenia $(16 \% / 26 \%)$, diarrhoea $(13 \% / 24 \%)$, leukopenia $(8 \% / 17 \%)$, peripheral sensory neuropathy $(6 \% / 4 \%)$, and decreased weight $(7 \% / 0 \%)$. Three $(3 \%)$ patients discontinued treatment due to an adverse event (mouth ulceration, left ventricular ejection fraction reduction, and acute renal failure). A total of six (5\%) patients died during treatment or within 28 days of the last dose of study medication; one patient in part 1 (neratinib $240 \mathrm{mg}$ dose) and three patients in part 2 group A died due to disease progression, and two patients in part 2 group A died due to an adverse event (pneumonia and pulmonary embolism).

\begin{tabular}{|c|c|c|c|c|c|}
\hline \multirow[b]{2}{*}{ Parameter, n (\%) } & \multicolumn{2}{|c|}{ Part 1} & \multicolumn{2}{|c|}{ Part 2} & \multirow[b]{2}{*}{ Total $(\mathbf{N}=110)$} \\
\hline & $\begin{array}{c}\text { Neratinib } \\
160 \mathrm{mg}+\text { paclitaxel } \\
(n=3)\end{array}$ & $\begin{array}{c}\text { Neratinib } \\
240 \mathrm{mg}+\text { paclitaxel } \\
(n=5)\end{array}$ & $\begin{array}{c}\text { Group } A^{a} \\
(n=71)\end{array}$ & $\begin{array}{c}\text { Group Bb } \\
(n=31)\end{array}$ & \\
\hline $\begin{array}{l}\text { Median neratinib treatment duration } \\
\text { (range), weeks }\end{array}$ & $12.3(8.1-24.3)$ & $15.0(4.3-63.4)$ & $48.1(0.1-144.4)$ & $52.3(7.7-147.3)$ & $47.9(0.1-147.3)$ \\
\hline $\begin{array}{l}\text { Median paclitaxel treatment duration } \\
\text { (range), weeks }\end{array}$ & $11.1(7.1-23.1)$ & $15.0(3.0-46.9)$ & $31.0(1.0-81.0)$ & $30.0(3.0-97.1)$ & $29.6(1.0-97.1)$ \\
\hline $\begin{array}{l}\text { Median neratinib dose intensity } \\
\text { (range), mg per day }\end{array}$ & $160.0(150.7-160.0)$ & $239.5(166.7-240.0)$ & $239.6(152.9-241.1)$ & $240.0(100.5-240.0)$ & $239.6(100.5-241.1)$. \\
\hline $\begin{array}{l}\text { Median paclitaxel dose intensity } \\
\text { (range), } \mathrm{mg} \mathrm{m}^{-2} \text { per cycle }\end{array}$ & $225.8(207.4-244.1)$ & $211.9(158.1-237.5)$ & $212.4(78.7-245.1)$ & $226.2(131.1-244.9)$ & $213.5(78.7-245.1)$ \\
\hline \multicolumn{6}{|l|}{ Neratinib dose modification } \\
\hline Dose delay & $1(33)$ & $3(60)$ & $42(59)$ & $12(39)$ & $58(53)$ \\
\hline Dose reduction & 0 & $1(20)$ & $13(18)$ & $7(23)$ & $21(19)$ \\
\hline Due to adverse event & 0 & $1(20)$ & $10(14)$ & $5(16)$ & $16(15)$ \\
\hline Other/not stated & 0 & 0 & $7(10)$ & $2(6)$ & 9 (8) \\
\hline \multicolumn{6}{|l|}{ Paclitaxel dose modification } \\
\hline Dose delay & $1(33)$ & $5(100)$ & $46(65)$ & $19(61)$ & $71(65)$ \\
\hline Dose reduction & $1(33)$ & $2(40)$ & $25(35)$ & $13(42)$ & $41(37)$ \\
\hline Due to adverse event & $1(33)$ & $2(40)$ & $25(35)$ & $12(39)$ & $40(36)$ \\
\hline Other/not stated & 0 & 0 & 0 & $1(3)$ & $1(1)$ \\
\hline
\end{tabular}


Overall, the combination of neratinib plus paclitaxel was associated with a safety and tolerability profile generally characteristic of each agent given as monotherapy. Although the safety analyses included patients from both parts 1 and 2 of the study, only three patients received a dosage lower than the MTD (i.e., neratinib $160 \mathrm{mg}$ per day plus paclitaxel). Neratinib has previously been associated with incidences of gastrointestinal events (i.e., diarrhoea, nausea, and vomiting), fatigue, and rash, (Wong et al, 2009; Burstein et al, 2010) with incidences similar to those observed in the current study. Although diarrhoea was the most common adverse event and grade $3 / 4$ adverse event observed with neratinib treatment in this study ( $92 \%$ all grades; $29 \%$ grade $3 /$ 4) and in previous studies ( $88 \%-93 \% ; 21 \%-32 \%)$, it typically occurred early (median time to onset of 2-8.5 days across studies) and was managed with dose adjustments and/or anti-diarrhoeal medications (Wong et al, 2009; Burstein et al, 2010). In addition, no patients stated diarrhoea as their primary reason for treatment discontinuation in this study, and it has only rarely been associated

Table 3. Treatment-emergent adverse events reported by $\geqslant 10 \%$ of patients, any causality

\begin{tabular}{|c|c|c|}
\hline \multirow[b]{2}{*}{ Adverse event, $\boldsymbol{n}(\%)$} & \multicolumn{2}{|c|}{ Total $(\mathbf{N}=110)^{a}$} \\
\hline & All grades & Grade $\geqslant 3$ \\
\hline Diarrhoea & $101(92)$ & $32(29)$ \\
\hline Peripheral sensory neuropathy & $56(51)$ & $3(3)$ \\
\hline Neutropenia & $55(50)$ & $22(20)$ \\
\hline Alopecia & $51(46)$ & 0 \\
\hline Leukopenia & $45(41)$ & $20(18)$ \\
\hline Anaemia & $41(37)$ & 9 (8) \\
\hline Nausea & $37(34)$ & $1(1)$ \\
\hline Rash & $32(29)$ & $1(1)$ \\
\hline Vomiting & $29(26)$ & $2(2)$ \\
\hline Decreased appetite & $28(25)$ & $1(1)$ \\
\hline Fatigue & $23(21)$ & $4(4)$ \\
\hline Peripheral oedema & $23(21)$ & $1(1)$ \\
\hline Pyrexia & $23(21)$ & 0 \\
\hline Cough & $21(19)$ & 0 \\
\hline Asthenia & $20(18)$ & $1(1)$ \\
\hline Stomatitis & $20(18)$ & 0 \\
\hline ALT increased & $17(15)$ & $4(4)$ \\
\hline Urinary tract infection & $17(15)$ & 0 \\
\hline AST increased & $14(13)$ & $3(3)$ \\
\hline Dyspnea & $14(13)$ & $4(4)$ \\
\hline Decreased weight & $13(12)$ & $1(1)$ \\
\hline Dyspepsia & $13(12)$ & 0 \\
\hline Headache & $13(12)$ & 0 \\
\hline Dizziness & $12(11)$ & $1(1)$ \\
\hline Hypokalemia & $12(11)$ & $3(3)$ \\
\hline Upper abdominal pain & $12(11)$ & 0 \\
\hline Abdominal pain & $11(10)$ & 0 \\
\hline Pain in extremity & $11(10)$ & 0 \\
\hline \multicolumn{3}{|c|}{$\begin{array}{l}\text { Abbreviations: ALT = alanine aminotransferase; AST = aspartate aminotransferase. } \\
\text { a Includes three patients from part } 1 \text { of the study who received neratinib } 160 \mathrm{mg} \text { per day plus } \\
\text { paclitaxel, who experienced grade } 3 / 4 \text { events of anaemia }(n=1) \text {, abdominal discomfort } \\
(n=1) \text {, and diarrhoea }(n=1) \text {. }\end{array}$} \\
\hline
\end{tabular}

with treatment discontinuation in prior neratinib monotherapy studies (Wong et al, 2009; Burstein et al, 2010).

Paclitaxel monotherapy has been associated with haematologic events (i.e., neutropenia, anaemia, and leukopenia), peripheral sensory neuropathy, alopecia, and gastrointestinal events (Wiseman and Spencer, 1998), and, as expected, these events were also seen with combination neratinib plus paclitaxel in the current study. Comparison of adverse events across multiple studies is difficult due to differences in patient population and study design (including treatment duration); however, the incidence (all grades; grade $3 / 4$ ) of adverse events observed in the current study compare favourably with those previously reported for combination studies of weekly paclitaxel $80 \mathrm{mg} \mathrm{m}^{-2}$ plus other anti-HER2 agents (i.e., trastuzumab or lapatinib): neutropenia ( $50 \%$ in current study vs $44-87 \%$ in prior studies; $20 \%$ vs $22-52 \%$ ), anaemia (37\% vs $43-$ $47 \% ; 8 \%$ vs $0-6 \%)$, leukopenia (41\% vs $41-92 \% ; 18 \%$ vs $11-31 \%)$, peripheral sensory neuropathy (51\% vs $25-86 \%$; $3 \%$ vs 0-6\%), and alopecia (46\% vs 89-94\%; 0\% vs 0-14\%; Perez et al, 2005; Furukawa et al, 2006; Gasparini et al, 2007; Han et al, 2009; Horiguchi et al, 2009; Jagiello-Gruszfeld et al, 2010). In addition, comparison of adverse events with those reported for paclitaxel monotherapy is difficult given that reported data are primarily for a different dose and schedule (i.e., paclitaxel $175 \mathrm{mg} \mathrm{m}^{-2}$ every 3 weeks; Wiseman and Spencer, 1998).

Overall, no unexpected toxicity was observed in patients receiving neratinib plus paclitaxel, with a safety profile that suggests no additional (i.e., synergistic) toxicity. Although toxicities previously associated with neratinib and/or paclitaxel were observed in the current study, few patients discontinued treatment due to toxicity.

Antitumour activity (part 2). A total of 99 patients from part 2 of the study were evaluated for antitumour activity. The ORR for all evaluable patients was $73 \%$ (95\% CI, 62.9\%-81.2\%), and included seven $(7 \%)$ patients who achieved a complete response and 65 (66\%) who achieved a partial response (Table 4). ORR rates were high among patients in both group A (71\%) and group B (77\%), including 23 of 33 (70\%) patients who received treatment in the first-line setting (Table 5). Among those who responded, the overall median duration of response was 73.0 weeks (range; 9.0-136.4 weeks); median duration of response in group A was 77.1 weeks and in group B was 56.3 weeks. An additional nine (9\%) patients achieved stable disease for at least 24 weeks, for a clinical

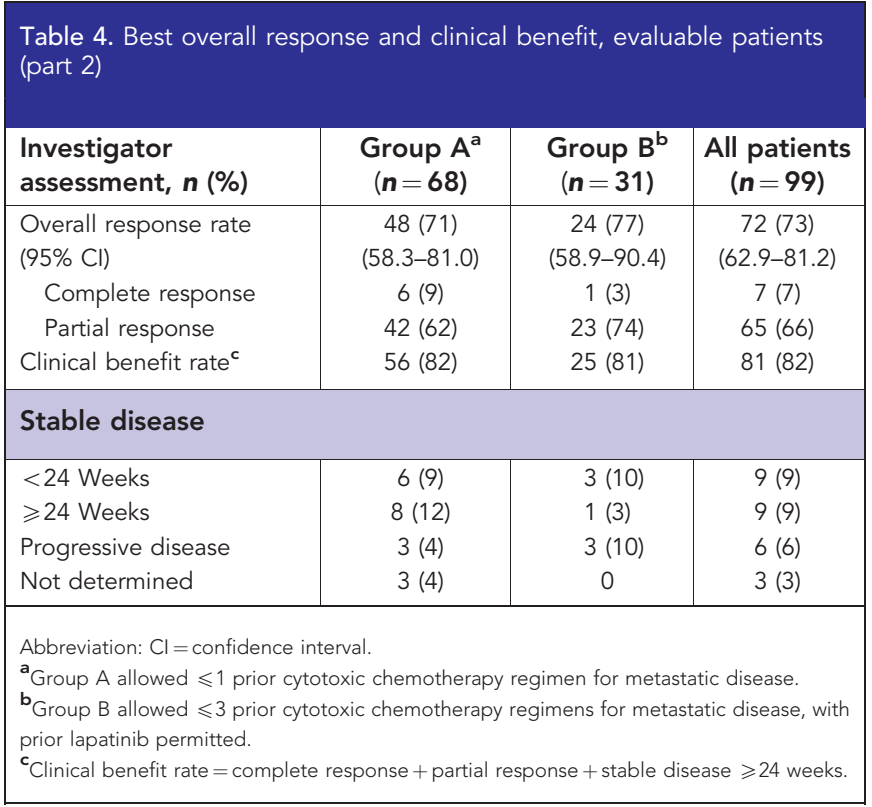


benefit rate of $82 \%$ (95\% CI: $72.8-88.9 \%$; Table 4 ). Few patients had a best overall response of progressive disease $(n=6(6 \%))$. Kaplan-Meier median PFS was 57.0 weeks (95\% CI: $47.7-81.6$ weeks) among all evaluable patients, and was similar between groups A and B (Figure 1).

The three patients from the ITT population $(n=102)$ who were not included in the evaluable population did not achieve a complete or partial response, or did they maintain stable disease for at least 24 weeks. Thus, the response rates in the ITT population were $7 \%(n=7)$ for complete response and $64 \%(n=65)$ for partial response, with an ORR of $71 \%$ (95\% CI: $60.7-79.2 \%)$. An additional $9 \%(n=9)$ of patients maintained stable disease for at least 24 weeks, leading to a clinical benefit rate of $79 \%$ (95\% CI: $70.3-86.8 \%$ ).

In the evaluable population, the ORR (73\%) for neratinib plus paclitaxel in the current study was noticeably higher than that observed for neratinib monotherapy in patients with advanced HER2-positive breast cancer (32-40\%); among responders, the median duration of response was 73.0 weeks vs 20.9-52.4 weeks, respectively (Wong et al, 2009; Burstein et al, 2010). The median time to PFS was also longer in the current study (57.0 weeks vs 15.7-39.6 weeks; Wong et al, 2009; Burstein et al, 2010). Although many of the patients in the prior studies were heavily pretreated $(\geqslant 4$ prior treatments; more similar to group B of the current study),

\section{Table 5. Overall response rate, efficacy subsets (part 2)}

\begin{tabular}{|c|c|c|c|c|c|}
\hline \multirow[b]{2}{*}{ Efficacy subsets } & \multirow[b]{2}{*}{$n$} & \multicolumn{2}{|c|}{ Overall response rate } & \multicolumn{2}{|c|}{ Progression-free survival } \\
\hline & & n (\%) & $95 \% \mathrm{Cl}$ & Median (weeks) & $95 \% \mathrm{Cl}$ \\
\hline \multicolumn{6}{|l|}{ Hormone receptor status } \\
\hline $\begin{array}{l}\text { ER/PR + } \\
\text { ER/PR - }\end{array}$ & $\begin{array}{l}55 \\
44\end{array}$ & $\begin{array}{l}46(84) \\
26(59)\end{array}$ & $\begin{array}{l}71.2-92.2 \\
43.2-73.7\end{array}$ & $\begin{array}{l}64.0 \\
47.7\end{array}$ & $\begin{array}{l}52.1-92.1 \\
29.9-91.9\end{array}$ \\
\hline \multicolumn{6}{|l|}{ Prior therapy status } \\
\hline $\begin{array}{l}\text { First-line therapy } \\
\text { Prior HER2-directed therapy } \\
\text { Prior trastuzumab therapy } \\
\text { Prior lapatinib therapy } \\
\text { Prior endocrine therapy } \\
\text { Prior taxane therapy }\end{array}$ & $\begin{array}{l}33 \\
38 \\
28 \\
14 \\
39 \\
62\end{array}$ & $\begin{array}{l}23(70) \\
27(71) \\
20(71) \\
10(71) \\
32(82) \\
50(81)\end{array}$ & $\begin{array}{l}51.3-84.4 \\
54.1-84.6 \\
51.3-86.8 \\
41.9-91.6 \\
66.5-92.5 \\
68.6-89.6\end{array}$ & $\begin{array}{l}57.0 \\
63.1 \\
94.9 \\
44.3 \\
52.1 \\
55.6\end{array}$ & $\begin{array}{l}44.1-90.4 \\
47.7-95.4 \\
55.1-\mathrm{NE} \\
23.4-64.0 \\
39.7-81.4 \\
40.4-87.7\end{array}$ \\
\hline
\end{tabular}

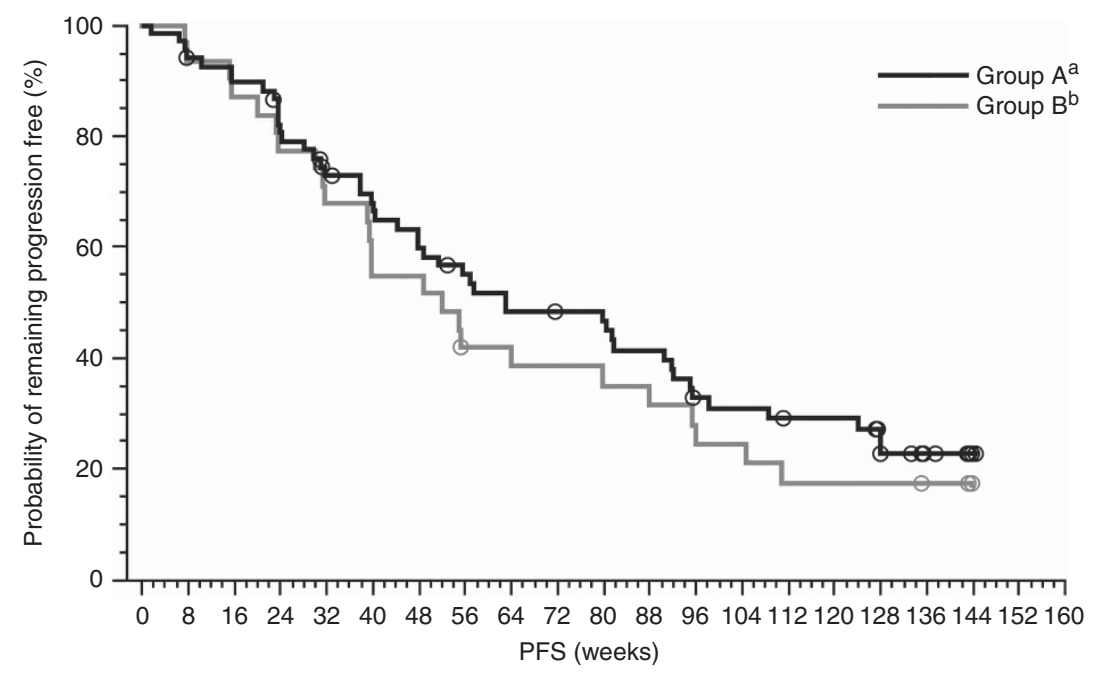

No. of patients at risk

$\begin{array}{lllllllllllllllllllll}\text { Group A } 68 & 63 & 60 & 53 & 46 & 42 & 37 & 33 & 29 & 28 & 27 & 24 & 18 & 17 & 15 & 15 & 12 & 5 & 1 & 0 & 0\end{array}$

Group B $\begin{array}{lllllllllllllllllllll}31 & 29 & 27 & 24 & 21 & 17 & 17 & 12 & 12 & 11 & 10 & 9 & 8 & 7 & 5 & 5 & 5 & 2 & 0 & 0 & 0\end{array}$

\begin{tabular}{lccc}
\hline Efficacy subets & $n$ & Median PFS & $95 \% \mathrm{Cl}$ \\
\hline All patients & 99 & 57.0 weeks & $47.7-81.6$ \\
Group A & 68 & 63.1 weeks & $47.7-92.1$ \\
Group B & 31 & 52.1 weeks & $39.0-87.7$ \\
\hline
\end{tabular}

Figure 1. PFS, evaluable patients (part 2). Kaplan-Meier median PFS was based on investigator assessments. Abbriviation: Cl, confidence interval. ${ }^{a}$ Group $A$ allowed $\leqslant 1$ prior cytotoxic chemotherapy regimen for metastatic disease. ${ }^{b}$ Group $B$ allowed $\leqslant 3$ prior cytotoxic chemotherapy regimens for metastatic disease, with prior lapatinib permitted. 


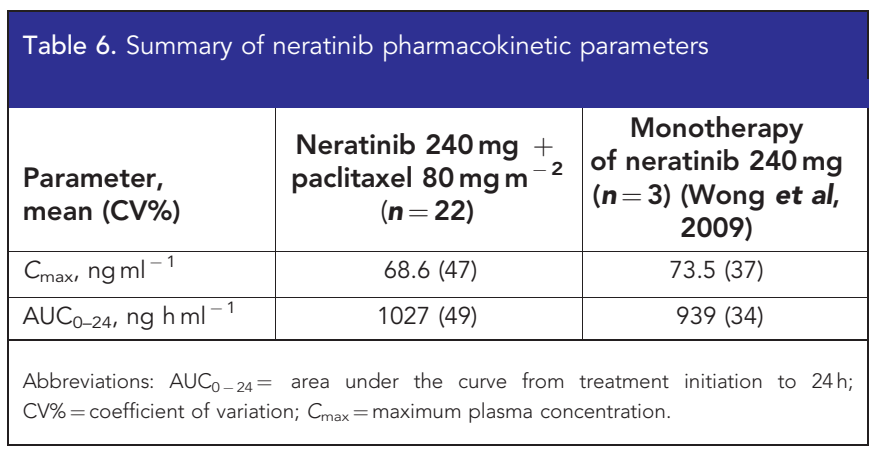

the antitumour activity observed for group B (ORR, 77\%; median PFS, 52.1 weeks) still compares favourably with the previous reports of neratinib monotherapy.

In the current study, secondary analyses indicated that the ORR and Kaplan-Meier median PFS were higher among patients with hormone receptor-positive disease ( $84 \%$ and 64.0 weeks) compared with those with hormone receptor-negative disease (59\% and 47.7 weeks; Table 5). The ORR remained high among patients with prior endocrine therapy (82\%), although Kaplan-Meier median PFS was shorter among patients with prior hormonal therapy (52.1 weeks) compared with those without (79.7 weeks).

Of 38 evaluable patients exposed to prior HER2-directed therapy in the current study, 27 responded (ORR, 71\%), including 20 of $28(71 \%)$ patients treated with prior trastuzumab and 10 of $14(71 \%)$ patients treated with prior lapatinib (Table 5). However, Kaplan-Meier median PFS among patients with prior HER2directed therapy was 63.1 weeks (95\% CI: 47.7-95.4 weeks), whereas those without prior HER2-directed therapy was 52.1 weeks (95\% CI: 39.7-81.4 weeks). A high rate of response (ORR, $81 \%$ ) and long Kaplan-Meier median PFS (55.6 weeks) was also observed in patients with prior taxane therapy.

The data suggest good clinical activity among subsets of patients with prior endocrine, HER2-directed, and/or taxane therapies who received neratinib plus paclitaxel in the current study. However, as the number of patients in each prior treatment subset was small in this study, these subset results should be interpreted with caution. A prior study of neratinib monotherapy in patients with HER2positive breast cancer with and without prior trastuzumab treatment indicated that neratinib had greater activity in those who were trastuzumab naive (ORR, 24\% vs 56\%; PFS, 22.3 vs 39.6 weeks, respectively; Burstein et al, 2010). Similarly, in a study of trastuzumab plus paclitaxel, response rates were lower among patients with prior taxane therapy compared with the overall study population (ORR, 37.7\% vs 20.0\%; Furukawa et al, 2006). In contrast, in the current study, response rates and median PFS for patients with prior HER2-directed therapy (trastuzumab and/or lapatinib) as well as prior taxane therapy were similar to those of the overall patient population.

Pharmacokinetics. In this study, the maximum plasma concentration $\left(C_{\max }\right)$ and area under the curve (AUC) from treatment initiation to $24 \mathrm{~h}\left(\mathrm{AUC}_{0-24}\right)$ of neratinib given in combination with paclitaxel were $68.6 \mathrm{ng} \mathrm{ml}^{-1}$ and $1027 \mathrm{ng} \mathrm{h} \mathrm{ml}^{-1}$ (Table 6). These neratinib exposures were similar to those previously observed for neratinib monotherapy in patients with solid tumours (Wong et al, 2009), suggesting that there is no interaction between neratinib and paclitaxel when administered in combination.

\section{CONCLUSIONS}

The combination of neratinib (240 mg per day) and paclitaxel (paclitaxel $80 \mathrm{mg} \mathrm{m}^{-2}$ ) was associated with apparently higher toxicity than that of neratinib as monotherapy but was manageable with antidiarrhoeal agents and dose reductions. Diarrhoea was the most common treatment-emergent adverse event (all grades and grade 3); however, it typically occurred early, was transient, and did not lead to treatment discontinuation. Despite the absence of interaction between neratinib and paclitaxel from pharmacokinetics, careful clinical monitoring of the treatment-emergent side effects is necessary. This combination also demonstrated a high rate of response in patients with HER2-positive breast cancer, including patients in both the first-line setting and the second-line or greater setting. The benefit and risk should be carefully evaluated in the future studies.

Nevertheless, results from this study support the further evaluation of neratinib combined with paclitaxel for the treatment of patients with HER2-positive breast cancer. A phase III trial is currently ongoing to study the combination of neratinib plus paclitaxel compared with trastuzumab plus paclitaxel in the firstline setting. Other ongoing or recently completed trials are assessing the activity of neratinib in combination with trastuzumab (Swaby et al, 2009), capecitabine (Saura et al, 2009), vinorelbine (Staroslawska et al, 2010), and temsirolimus (Gandhi et al, 2011) in HER2-positive breast cancer or other solid tumours.

\section{ACKNOWLEDGEMENTS}

We thank Drs Zefei Jiang and Junlan Yang for their significant contributions to this study. This study (Study 3144A1-203/ B1891014 (ClinicalTrials.gov \#NCT00445458)) was initially sponsored by Wyeth Research, which was acquired by Pfizer in October 2009; through the work of authors who are/were employees of Pfizer (AF, YZ, RA, and M-LVV), Pfizer has contributed to all stages of this study as well as manuscript preparation. Sponsorship was transferred to PUMA Biotechnology under a licensing agreement on 10 April 2012. Editorial/medical writing support was provided by Kimberly Brooks, $\mathrm{PhD}$, of SciFluent, and was funded by Pfizer.

\section{CONFLICT OF INTEREST}

SG has served as an advisor/consultant for Pfizer. RA and MLV are employees of Pfizer and AF and YZ are former employees of Pfizer; $\mathrm{YZ}$ and RA additionally own stock in Pfizer. The remaining authors (LC, BX, and IB) declare no conflict of interest.

\section{AUTHOR CONTRIBUTIONS}

LW-CC, YZ, and RA assisted with the conception and design of the study. LW-CC, BX, AF, RA, MLVV, and IB collected and assembled data for the study, and all authors assisted in the analysis and/or interpretation of the data. All authors have participated in the writing and/or critical revision of this manuscript and have approved the final manuscript for publication.

\section{REFERENCES}

Andersson M, Lidbrink E, Bjerre K, Wist E, Enevoldsen K, Jensen AB, Karlsson P, Tange UB, Sørensen PG, Møller S, Bergh J, Langkjer ST (2011) Phase III randomized study comparing docetaxel plus trastuzumab with vinorelbine plus trastuzumab as first-line therapy of metastatic or locally advanced human epidermal growth factor receptor 2-positive breast cancer: the HERNATA study. J Clin Oncol 29(3): 264-271.

Andre F, Campone M, O'Regan R, Manlius C, Massacesi C, Sahmoud T, Mukhopadhyay P, Soria JC, Naughton M, Hurvitz SA (2010) Phase I study 
of everolimus plus weekly paclitaxel and trastuzumab in patients with metastatic breast cancer pretreated with trastuzumab. J Clin Oncol 28(34): 5110-5115.

Benson 3rd AB, Ajani JA, Catalano RB, Engelking C, Kornblau SM, Martenson Jr JA, McCallum R, Mitchell EP, O’Dorisio TM, Vokes EE, Wadler S (2004) Recommended guidelines for the treatment of cancer treatment-induced diarrhea. J Clin Oncol 22(14): 2918-2926.

Blackwell KL, Burstein HJ, Storniolo AM, Rugo H, Sledge G, Koehler M, Ellis C, Casey M, Vukelja S, Bischoff J, Baselga J, O’Shaughnessy J (2010) Randomized study of lapatinib alone or in combination with trastuzumab in women with ErbB2-positive, trastuzumab-refractory metastatic breast cancer. J Clin Oncol 28(7): 1124-1130.

Burstein HJ, Keshaviah A, Baron AD, Hart RD, Lambert-Falls R, Marcom PK, Gelman R, Winer EP (2007) Trastuzumab plus vinorelbine or taxane chemotherapy for HER2-overexpressing metastatic breast cancer: the trastuzumab and vinorelbine or taxane study. Cancer 110(5): 965-972.

Burstein HJ, Storniolo AM, Franco S, Forster J, Stein S, Rubin S, Salazar VM, Blackwell KL (2008) A phase II study of lapatinib monotherapy in chemotherapy-refractory HER2-positive and HER2-negative advanced or metastatic breast cancer. Ann Oncol 2008 19(6): 1068-1074.

Burstein HJ, Sun Y, Dirix LY, Jiang Z, Paridaens R, Tan AR, Awada A, Ranade A, Jiao S, Schwartz G, Abbas R, Powell C, Turnbull K, Vermette J, Zacharchuk C, Badwe R (2010) Neratinib, an irreversible ErbB receptor tyrosine kinase inhibitor, in patients with advanced ErbB2-positive breast cancer. J Clin Oncol 28(8): 1301-1307.

Cameron D, Casey M, Press M, Lindquist D, Pienkowski T, Romieu CG, Chan S, Jagiello-Gruszfeld A, Kaufman B, Crown J, Chan A, Campone M, Viens P, Davidson N, Gorbounova V, Raats JI, Skarlos D, Newstat B, Roychowdhury D, Paoletti P, Oliva C, Rubin S, Stein S, Geyer CE (2008) A phase III randomized comparison of lapatinib plus capecitabine $v s$ capecitabine alone in women with advanced breast cancer that has progressed on trastuzumab: updated efficacy and biomarker analyses. Breast Cancer Res Treat 112(3): 533-543.

Di Leo A, Gomez HL, Aziz Z, Zvirbule Z, Bines J, Arbushites MC, Guerrera SF, Koehler M, Oliva C, Stein SH, Williams LS, Dering J, Finn RS, Press MF (2008) Phase III, double-blind, randomized study comparing lapatinib plus paclitaxel with placebo plus paclitaxel as first-line treatment for metastatic breast cancer. J Clin Oncol 26(34): $5544-5552$.

Eiermann W (2001) Trastuzumab combined with chemotherapy for the treatment of HER2-positive metastatic breast cancer: pivotal trial data. Ann Oncol 12(Suppl 1): S57-S62.

Furukawa K, Ito Y, Takahashi S, Sawaki M, Mizunuma N, Horikoshi N, Kasumi F, Akiyama F, Sakamoto G, Furukawa K, Tajiri T, Hatake K (2006) Efficacy and safety of combined trastuzumab and paclitaxel therapy as a second-line treatment in women with metastatic breast cancer: a single institutional experience. Breast Cancer 13(4): 329-333.

Gandhi L, Bahleda R, Cleary JM, Hollebecque A, Kwak EL, Pandya S, Tolaney S, Abbas R, Ananthakrishnan R, Berkenblit A, Boni J, Clancy J, Turnbull KW, Vo Van M, Shapiro G, Soria J (2011) Two-dimensional phase I study of neratinib (NER) combined with temsirolimus (TEM) in patients (Pts) with solid tumors. J Clin Oncol 29(15 Suppl): 3027.

Gasparini G, Gion M, Mariani L, Papaldo P, Crivellari D, Filippelli G, Morabito A, Silingardi V, Torino F, Spada A, Zancan M, De SL, Caputo A, Cognetti F, Lambiase A, Amadori D (2007) Randomized phase II trial of weekly paclitaxel alone $v s$ trastuzumab plus weekly paclitaxel as first-line therapy of patients with Her-2 positive advanced breast cancer. Breast Cancer Res Treat 101(3): 355-365.

Geyer CE, Forster J, Lindquist D, Chan S, Romieu CG, Pienkowski T, JagielloGruszfeld A, Crown J, Chan A, Kaufman B, Skarlos D, Campone M, Davidson N, Berger M, Oliva C, Rubin SD, Stein S, Cameron D (2006) Lapatinib plus capecitabine for HER2-positive advanced breast cancer. N Engl J Med 355(26): 2733-2743.

Han HS, Kim JS, Park JH, Jeon YK, Lee KW, Oh DY, Kim JH, Park SY, Im SA, Kim TY, Park IA, Bang YJ (2009) Weekly paclitaxel and trastuzumab as a first-line therapy in patients with HER2-overexpressing metastatic breast cancer: magnitude of HER2/neu amplification as a predictive factor for efficacy. J Korean Med Sci 24(5): 910-917.

Horiguchi J, Oyama T, Koibuchi Y, Yokoe T, Takata D, Ikeda F, Nagaoka H, Rokutanda N, Nagaoka R, Ishikawa Y, Odawara H, Kikuchi M, Sato A, Iino Y, Takeyoshi I (2009) Neoadjuvant weekly paclitaxel with and without trastuzumab in locally advanced or metastatic breast cancer. Anticancer Res 29(2): 517-524.
Jagiello-Gruszfeld A, Tjulandin S, Dobrovolskaya N, Manikhas A, Pienkowski T, DeSilvio M, Ridderheim M, Abbey R (2010) A single-arm phase II trial of first-line paclitaxel in combination with lapatinib in HER2-overexpressing metastatic breast cancer. Oncology 79(1-2): 129-135.

Jemal A, Siegel R, Xu J, Ward E (2010) Cancer statistics, 2010. CA Cancer J Clin 60(5): 277-300.

Kwak EL, Sordella R, Bell DW, Godin-Heymann N, Okimoto RA, Brannigan BW, Harris PL, Driscoll DR, Fidias P, Lynch TJ, Rabindran SK, McGinnis JP, Wissner A, Sharma SV, Isselbacher KJ, Settleman J, Haber DA (2005) Irreversible inhibitors of the EGF receptor may circumvent acquired resistance to gefitinib. Proc Natl Acad Sci USA 102(21): 7665-7670.

Marty M, Cognetti F, Maraninchi D, Snyder R, Mauriac L, Tubiana-Hulin M, Chan S, Grimes D, Anton A, Lluch A, Kennedy J, O’Byrne K, Conte P, Green M, Ward C, Mayne K, Extra JM (2005) Randomized phase II trial of the efficacy and safety of trastuzumab combined with docetaxel in patients with human epidermal growth factor receptor 2-positive metastatic breast cancer administered as first-line treatment: the M77001 study group. J Clin Oncol 23(19): 4265-4274.

Perez EA, Suman VJ, Rowland KM, Ingle JN, Salim M, Loprinzi CL, Flynn PJ, Mailliard JA, Kardinal CG, Krook JE, Thrower AR, Visscher DW, Jenkins RB (2005) Two concurrent phase II trials of paclitaxel/carboplatin/ trastuzumab (weekly or every-3-week schedule) as first-line therapy in women with HER2-overexpressing metastatic breast cancer: NCCTG study 983252. Clin Breast Cancer 6(5): 425-432.

Rabindran SK, Discafani CM, Rosfjord EC, Baxter M, Floyd MB, Golas J, Hallett WA, Johnson BD, Nilakantan R, Overbeek E, Reich MF, Shen R, Shi X, Tsou HR, Wang YF, Wissner A (2004) Antitumor activity of HKI272 , an orally active, irreversible inhibitor of the HER-2 tyrosine kinase. Cancer Res 64(11): 3958-3965.

Robert N, Leyland-Jones B, Asmar L, Belt R, Ilegbodu D, Loesch D, Raju R, Valentine E, Sayre R, Cobleigh M, Albain K, McCullough C, Fuchs L, Slamon D (2006) Randomized phase III study of trastuzumab, paclitaxel, and carboplatin compared with trastuzumab and paclitaxel in women with HER-2-overexpressing metastatic breast cancer. J Clin Oncol 2006 24(18): 2786-2792.

Saura C, Martin M, Moroose R, Harb W, Liem K, Arena F, Gressler V, Cortes J, Wade M, Powell C, Shapiro M (2009) Safety of neratinib (HKI-272) in combination with capecitabine in patients with solid tumors: a phase 1/2 study. Cancer Res 69(24 suppl): 5108 .

Seidman AD, Berry D, Cirrincione C, Harris L, Muss H, Marcom PK, Gipson G, Burstein H, Lake D, Shapiro CL, Ungaro P, Norton L, Winer E, Hudis C (2008) Randomized phase III trial of weekly compared with every-3-weeks paclitaxel for metastatic breast cancer, with trastuzumab for all HER-2 overexpressors and random assignment to trastuzumab or not in HER-2 nonoverexpressors: final results of Cancer and Leukemia Group B protocol 9840. J Clin Oncol 26(10): 1642-1649.

Sirotnak FM, Zakowski MF, Miller VA, Scher HI, Kris MG (2000) Efficacy of cytotoxic agents against human tumor xenografts is markedly enhanced by coadministration of ZD1839 (Iressa), an inhibitor of EGFR tyrosine kinase. Clin Cancer Res 6(12): 4885-4892.

Slamon DJ, Clark GM, Wong SG, Levin WJ, Ullrich A, McGuire WL (1987) Human breast cancer: correlation of relapse and survival with amplification of the HER-2/neu oncogene. Science 235(4785): 177-182.

Slamon DJ, Leyland-Jones B, Shak S, Fuchs H, Paton V, Bajamonde A, Fleming T, Eiermann W, Wolter J, Pegram M, Baselga J, Norton L (2001) Use of chemotherapy plus a monoclonal antibody against HER2 for metastatic breast cancer that overexpresses HER2. N Engl J Med 344(11): 783-792.

Staroslawska E, Dirix L, Luu T, Dieras V, Manso L, Xu B, Yang J, Berkenblit A, Agrapart V, Vo Van M-L, Powell C, Ananthakrishnan R, Abbas R, Awada A (2010) Safety and efficacy of neratinib (HKI-272) plus vinorelbine in the treatment of patients with ErbB2 + metastatic breast cancer with anti-Her2 therapy. Cancer Res 70(24 Suppl): P3-14-05.

Swaby R, Blackwell K, Jiang Z, Sun Y, Dieras V, Zaman K, Zacharchuk C, Powell C, Abbas R, Thakuria M (2009) Neratinib in combination with trastuzumab for the treatment of advanced breast cancer: a phase I/II study. J Clin Oncol 27(15S): 1004.

Toi M, Iwata H, Fujiwara Y, Ito Y, Nakamura S, Tokuda Y, Taguchi T, Rai Y, Aogi K, Arai T, Watanabe J, Wakamatsu T, Katsura K, Ellis CE, Gagnon RC, Allen KE, Sasaki Y, Takashima S (2009) Lapatinib monotherapy in patients with relapsed, advanced, or metastatic breast cancer: efficacy, safety, and biomarker results from Japanese patients phase II studies. Br J Cancer 101(10): 1676-1682. 
Tsou HR, Overbeek-Klumpers EG, Hallett WA, Reich MF, Floyd MB, Johnson BD, Michalak RS, Nilakantan R, Discafani C, Golas J, Rabindran SK, Shen R, Shi X, Wang YF, Upeslacis J, Wissner A (2005) Optimization of 6,7-disubstituted-4-(arylamino)quinoline-3-carbonitriles as orally active, irreversible inhibitors of human epidermal growth factor receptor-2 kinase activity. J Med Chem 48(4): 1107-1131.

Van Schaeybroeck S, Kyula J, Kelly DM, Karaiskou-McCaul A, Stokesberry SA, Van CE, Longley DB, Johnston PG (2006) Chemotherapy-induced epidermal growth factor receptor activation determines response to combined gefitinib/chemotherapy treatment in non-small cell lung cancer cells. Mol Cancer Ther 5(5): 1154-1165.

Wiseman LR, Spencer CM (1998) Paclitaxel. An update of its use in the treatment of metastatic breast cancer and ovarian and other gynaecological cancers. Drugs Aging 12(4): 305-334.
Wong KK, Fracasso PM, Bukowski RM, Lynch TJ, Munster PN, Shapiro GI, Janne PA, Eder JP, Naughton MJ, Ellis MJ, Jones SF, Mekhail T,

Zacharchuk C, Vermette J, Abbas R, Quinn S, Powell C, Burris HA (2009) A phase I study with neratinib (HKI-272), an irreversible pan ErbB receptor tyrosine kinase inhibitor, in patients with solid tumors. Clin Cancer Res 15(7): 2552-2558.

This work is published under the standard license to publish agreement. After 12 months the work will become freely available and the license terms will switch to a Creative Commons Attribution-NonCommercial-Share Alike 3.0 Unported License.

Supplementary Information accompanies this paper on British Journal of Cancer website (http://www.nature.com/bjc) 